\title{
Proemio
}

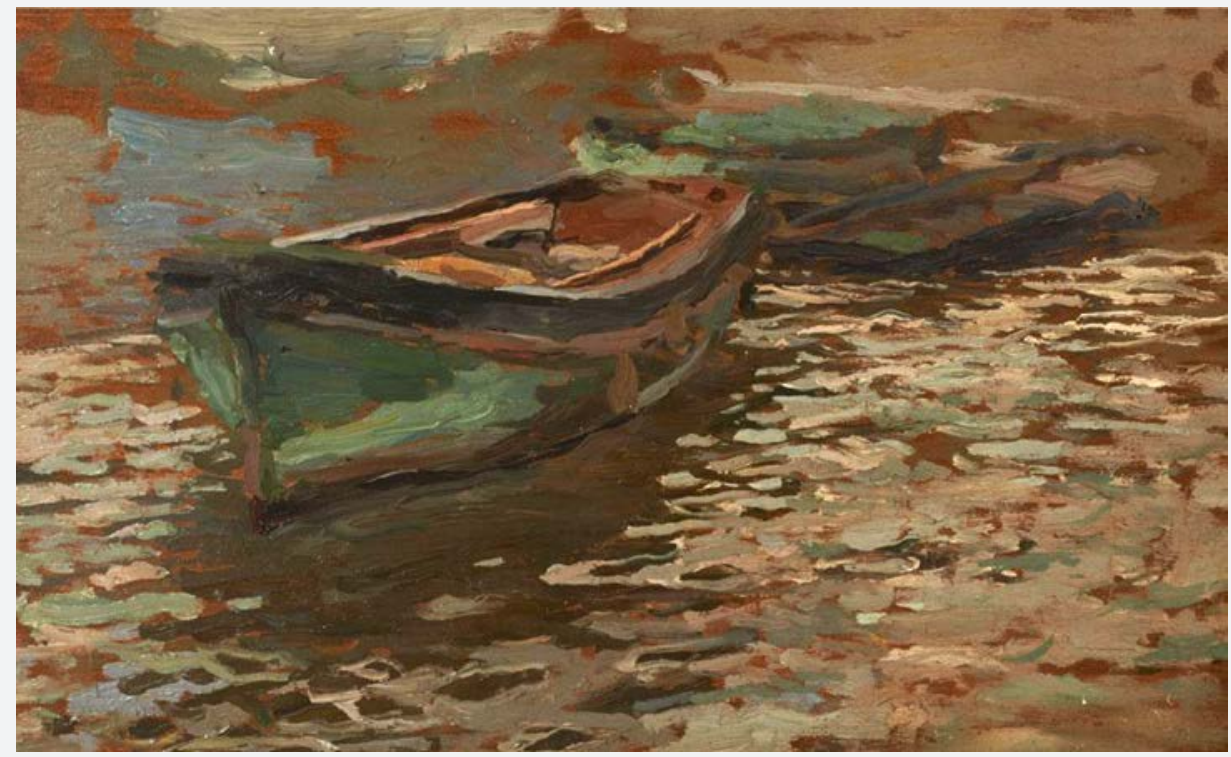

Del puerto viejo, Carlos Federico Sáez (Mercedes 1878 - Montevideo I90I), Óleo sobre tabla, $28 \times 18 \mathrm{~cm}$., Museo Nacional de Artes Visuales de Uruguay.

\section{Revistas culturales en tiempos de guerra ${ }^{1}$}

\author{
Cultural magazines in times of war
}

\section{Revistas culturais em tempos de guerra}


Desde el culto al pasado guerrero y los monumentos épicos que contribuyen a los discursos de identidad de los Estados-nacionales, hasta el arraigo de las metáforas militares del enemigo y la guerra en el discurso público en torno a la delincuencia o la enfermedad, lo bélico se revela como una trama ubicua, de enorme vigor semántico y plena de vigencia. Componente central del imaginario de la catástrofe, la guerra ha interpelado largamente a filósofos, historiadores y artistas, quienes han procurado diseccionar el motor de la destrucción material y la aniquilación del otro, al tiempo que registrar los alcances del horror y del trauma. A pesar de la complejidad que reviste el fenómeno, el abordaje científico más tradicional (vinculado con la historia militar) determinó que su comprensión se enfocara en aspectos relacionados con la defensa y seguridad nacional, la estrategia, el armamento y los medios técnicos al servicio del combate, los hitos, las batallas y los grandes personajes. Según han apuntado Miguel Alonso y David Alegre, la consolidación de la guerra como campo de estudio no tuvo lugar sino hasta después de la Segunda Guerra Mundial y a partir de indagaciones arraigadas en el ámbito de la sociología. Este primer desarrollo procuró dar cuenta de la etiología de los conflictos con la finalidad de generar una inteligencia o conocimiento de los enfrentamientos bélicos que sirviera para evitarlos. El impulso se vio enriquecido, a principios de los años sesenta, con la creación del Departamento de Estudios de la Guerra del King's College London, cuyo principal aporte podría cifrarse en la incorporación de nuevos ángulos de indagación a los practicados tradicionalmente. ${ }^{2}$

En el último tiempo, los fenómenos bélicos han venido concitando una atención remozada en el mundo académico, en parte, a raíz de la urgencia y centralidad de los estudios sobre la violencia, pero también debido a la renovación de la historia militar. Continuando con lo que han apuntado Alonso y Alegre, este último aspecto y la propia delimitación del campo de estudios de la guerra como un área de indagación que excede lo militar, han permitido que este territorio marginado «durante décadas por los círculos académicos como algo anticuado» haya conquistado «cierto grado de respetabilidad en el seno de la comunidad investigadora». ${ }^{3}$

\footnotetext{
2 Miguel Alonso Ibarra y David Alegre Lorenz, "Introducción: ciclos bélicos largos, guerra total y violencia de masas", en Europa desgarrada. Guerra, ocupación y violencia, 1900-1950, coords. David Alegre, Miguel Alonso y Javier Rodrigo. (Zaragoza: Prensas de la Universidad de Zaragoza, 2018), 10.

3 Alonso Ibarra y Alegre Lorenz, "Introducción”, 12.
} 
Fue fundamental, a estos efectos, la ampliación de las perspectivas de estudio. Lo que otrora se describía como una disciplina muy acotada en el ámbito de las humanidades ahora se delimita como un campo multidisciplinar que incorpora tendencias antropológicas, sociales y culturales, enfoques estos que contribuyen a iluminar factores y aspectos de los conflictos poco atendidos hasta el momento como la dimensión experiencial (enriquecida por las investigaciones en cultura material e historia de las emociones), la vida cotidiana en los frentes domésticos, el papel de actores históricos no militares o el mundo de la cultura durante la guerra, entre otros.

Esa apertura de nuevos horizontes para pensar los fenómenos bélicos, unida a la profusión de escritos, discursos e imágenes en torno de estos, habilita la pregunta por el papel de los intelectuales, las instituciones culturales y los impresos en tiempos de conflicto. Ya Pourquoi la guerre? (1933), el intercambio en el que Alfred Einstein y Sigmund Freud procuraron alcanzar algunas claves que contribuyeran a la pacificación del mundo, rodeaba esta cuestión al incluir, junto a la matriz instintiva de la agresividad humana (los mecanismos psíquicos que alimentan las pulsiones del odio y la destrucción en los hombres y con ello el cíclico retorno de las masacres), el peso de factores de índole social y cultural, como el derecho, las ideologías, el nacionalismo y la influencia ejercida por un conjunto de minorías en la instalación de la violencia de masas. Entre esos grupos, se identifica a la élite conocida como intelligentsia, cuya acción en tiempos de guerra - mediante operaciones de propaganda, persuasión, glorificación, legitimación, rechazo y solidaridad - podría seguirse a través del papel impreso. ${ }^{4}$ Es claro que el debate entre estas personalidades destacadas de la ciencia, como lo eran Freud y Einstein, respondía a una preocupación del campo intelectual europeo del periodo de entreguerras, pero la escena bien puede leerse como una representación de las tensiones seculares entre la guerra y la cultura, entre la violencia y lo civilizatorio.

En el ámbito particular de la historia cultural latinoamericana, las relaciones entre la guerra y la vida intelectual aguardan una mayor atención crítica, habida cuenta del extenso y diverso archivo escritural 
disponible. ${ }^{5}$ De éste emerge una fuente y soporte de enorme utilidad para indagar en el papel de los intelectuales en la configuración epistemológica, política y afectiva de los conflictos bélicos: las revistas culturales. La elevada capacidad para producir discursos, configurar redes y comunidades lectoras hace de estas publicaciones periódicas un insumo de gran interés para el estudio de posicionamientos, ideas y representaciones, así como para la profundización en el fenómeno de desterritorialización y expansión de la guerra en comunidades distantes. ${ }^{6}$ Las revistas podrían, asimismo, obrar como complemento de otras fuentes igualmente relevantes para el estudio de la experiencia colectiva de la violencia, como los documentos oficiales, la correspondencia privada, las memorias, los diarios personales, y los periódicos. Si bien se admite que comparten ciertas funciones con estos últimos, las peculiaridades materiales, de circulación, público, intereses y periodicidad permiten a las revistas culturales sostener un espacio de debates distintos de aquellos concebidos en la inmediatez exigida por la industria de la noticia. Además, debido a su potencia como usinas o laboratorios intelectuales y creativos recurren a estrategias editoriales distintas de las que se comprueban en las textualidades informativas $y$, por ende, ponen en juego otro tipo de mediación cultural y de influencia sobre la formación de sensibilidades y de opinión pública ante los enfrentamientos.

Atendiendo al encuadre temático expuesto, el dossier que abre este número 9 de Humanidades presenta cuatro trabajos que exploran la acción de diversos proyectos editoriales en formato revista en contextos de guerra. Los artículos revelan, mediante el estudio de soportes producidos en distintas geografías (Francia, Argentina y Chile), repercusiones, posicionamientos y silencios en torno a conflictos bélicos acaecidos durante los siglos XIX y XX.

En la primera contribución, Paula Bruno examina el impacto de la guerra hispano-norteamericana

5 Entre los trabajos que han avanzado sobre las relaciones entre guerra y cultura en el caso latinoamericano, se recomiendan los siguientes: Fernando Martínez-Pinzón y Javier Uriarte, eds., Entre el humo y la niebla. Guerra y cultura en América Latina (Pittsburg: Instituto Internacional de Literatura Iberoamericana, 2016); Fernando Degiovanni, Vernacular Latin Americanisms: War, the Market, and the Making of a Discipline (Pittsburgh: Pittsburgh University Press, 2019); Antonia Viu, "Lloremos y traduzcamos. La Segunda Guerra Mundial y la Cooperación Intelectual desde Babel. Revista de revistas (1939-1940)", en Homo dolens. Cartografías del dolor: sentidos, experiencias, registros, eds. Rafael Gaune y Claudio Rolle (Santiago de Chile: Fondo de Cultura Económica, 2018), 418-434.

6 Como ha aseverado Mary Favret, la capacidad para afectar, para invadir, la vida cotidiana en los frentes domésticos y zonas incluso más remotas a través del arte, la literatura y el periodismo representa un rasgo constitutivo de la guerra moderna. Mary Favret, War at a distance. Romanticism and the Making of Modern Warfare (New Jersey: Princeton University Press, 2010). 
de 1898 en Buenos Aires a partir del estudio de tres publicaciones del período (La Biblioteca, La Ilustración Sud-Americana y la Revista de Derecho, Historia y Letras). La irrupción del conflicto dentro del campo editorial y periodístico local, según lo analizado por la autora, se evidencia en las numerosas y heterogéneas intervenciones intelectuales (narración del conflicto desde voces militares y civiles, relatos de viaje, reproducción de conferencias de la época, migración textual de otros soportes coetáneos, etc.) que intentan presentar en el espacio público un posicionamiento particular frente a la guerra, a la vez que conformar «repertorios identitarios» de alcance regional (latinoamericanismo, hispanoamericanismo, antiimperialismo latinoamericano). De tal forma, se logra comprender cómo un universo letrado ajeno al conflicto se apropia de su contenido y busca otorgarle un sentido, que se asocia con la búsqueda de una identidad americana que cuestiona y reconfigura sus vínculos con las dos naciones beligerantes.

En segundo lugar, Gabriel Cid Rodríguez orienta su artículo al análisis y comprensión de las representaciones sobre la Guerra del Pacífico en revistas culturales chilenas de la postguerra (18981912). Mediante la revisión de un amplio corpus de publicaciones y desde la perspectiva de la historia cultural de la guerra, el texto explica de qué forma el proceso modernizador de la prensa periódica en el país y la irrupción de una nueva intelectualidad (la generación del 1900) en el campo cultural chileno coinciden con la construcción de un imaginario triunfante, de carácter nacionalista-patriótico que, desde el presente, intenta recuperar hitos y personajes de un pasado glorioso. En su estudio, el autor también identifica y examina en estos medios de comunicación los distintos mecanismos de intervención intelectual (biografías, cuentos, crónicas, testimonios, poemas, obras teatrales e ilustraciones), los cuales propenden, a partir de la imagen y la palabra, a la glorificación de la nación y a la consolidación de un relato fundante e identitario. La Guerra del Pacífico se convierte así, en la mirada de Cid Rodríguez, en el proceso histórico catalizador que permite a los nuevos escritores (asociados a escultores, dibujantes, grabadores, pintores y fotógrafos) contrastar la actualidad decadente frente a la hegemonía que impuso a nivel regional el triunfo sobre Perú y Bolivia, y que recupera los valores asociados a aquella victoria.

El trabajo de Juan Recchia Paez, por su parte, propone un acercamiento a la proyección de la Guerra de Canudos (1893-1897) 
fuera de las fronteras nacionales, a través del estudio del discurso expuesto en la parisina Revue du Brésil (París, 1896-1898). El análisis repara en las palabras y los silencios que rodean a estos relatos - que se procesan en simultáneo al desarrollo del propio enfrentamiento-, en la medida en que ponen en juego la imagen de la recientemente creada República brasileña. Según el autor, ante el impacto internacional y el interés lector respecto del conflicto bahiano, la revista se presenta como un espacio de defensa y legitimación del nuevo régimen ante las voces que lo cuestionan en el Viejo Continente, procesándose, de este modo, una «puesta en escena» discursiva, que asocia el nuevo régimen político con los ideales de civilización y modernidad de raigambre europea (construyendo hitos, personajes y símbolos asociados a ella), y que confronta a otros relatos que intentan disputarle la legitimidad dentro del universo periodístico de la opinión pública.

El monográfico concluye con el estudio de Sofía Mercader, que aborda, desde la perspectiva de la historia intelectual, el posicionamiento de la revista Punto de Vista ante el conflicto de Malvinas. En un recorrido que exhibe las características del espacio cultural argentino y del contexto histórico que lo contiene, la autora conceptualiza los principales debates que mantiene la intelectualidad respecto al gobierno militar y sus implicancias en el conflicto con las islas para demostrar cómo la mirada de Punto de Vista (1978) se aleja del relato hegemónico para constituirse en trinchera de resistencia frente a la entrada en la guerra y al fervor patriótico que atraviesa transversalmente a la sociedad argentina. El trabajo de Mercader sitúa históricamente las principales ideas de sus artífices dentro del universo letrado, en un despliegue de larga duración que logra trascender al conflicto para recoger también miradas retrospectivas de aquel posicionamiento y comprender de qué forma el fracaso que rodeó a la guerra fue visto por la publicación como condición necesaria para la salida democrática.

Complementan el dossier tres trabajos reunidos en la sección «Artículos», los que dan continuidad al hilo temático a través de su atención a uno de los tres vectores que vertebran esta propuesta (revistas, intelectuales, guerra). Así, Verónica Idrovo González examina los conceptos de América y república dentro de la Revista del Nuevo Mundo (1857), publicación dirigida por el intelectual chileno Francisco Bilbao. Desde la historia conceptual, la autora percibe el espacio de la revista como plataforma creativa 
y consagratoria, y como ámbito de enunciación y circulación de los fundamentos de ambas ideas, en medio de una coyuntura que interseca el proceso de organización nacional con los proyectos de unidad americana. Asimismo, la apuesta investigativa recupera un periodo importante, aunque no tan estudiado, de la vida de Bilbao para posicionarlo como un agente activo en la elaboración del discurso político-intelectual decimonónico que conecta los dos conceptos y los impone como un «horizonte de expectativa» de las nuevas comunidades postrevolucionarias.

En el caso de Ingrid Sánchez Téllez, su trabajo invita a la comprensión del papel de las novelas de folletín en el surgimiento del intelectual público en el campo cultural francés de finales del siglo XIX. El recorrido plantea un análisis de los contextos de producción de las novelas y sus condiciones de circulación en el mundo publicitario galo. Al satisfacer los gustos lectores de un público en continuo crecimiento y diversificación, la literatura de folletín popularizó la lectura de forma transversal en la sociedad francesa decimonónica y favoreció la fijación de un nuevo estatus para sus autores, los que, al ser percibidos como intérpretes de la realidad, trascendieron su condición de novelistas para encarnar la naciente idea del intelectual moderno.

El último artículo que conforma la sección presenta la investigación de Matías Emiliano Casas, en la cual se reconstruyen, a partir de un cuantioso y heterogéneo corpus, los entramados vinculares existentes entre los tradicionistas rioplatenses en el período 1927-1948. El estudio analiza el surgimiento de estos grupos, los contactos entre los diversos agentes que los conforman y sus dinámicas interactivas, en aras de comprender la transnacionalidad del movimiento y percibir la centralidad de algunos de sus actores, a la vez que la vinculación entre las manifestaciones privadas y estatales en torno a la consagración y conservación de dicha tradición rural y gauchesca y a la configuración, a su alrededor, de una identidad común argentino-uruguaya.

Este número de Humanidades se completa con una reseña bibliográfica y una entrevista. La primera, a cargo de Claudia Darrigrandi, se enfoca en el libro de Horacio Tarcus Las revistas culturales latinoamericanas. Giro material, tramas intelectuales y redes revisteriles (2020). De acuerdo con la lectura crítica exhaustiva que propone Darrigrandi, esta nueva obra de Tarcus, investigador argentino de reconocida trayectoria en el campo de las revistas culturales, reviste un 
gran interés por la labor teorizante y acumulativa de su propuesta, la que representa así una síntesis de lo avanzado en la investigación sobre estos soportes hasta el momento. Por su parte, la entrevista que cierra el número contiene un intercambio entre los editores y la investigadora argentina María Inés Tato, quien encabeza actualmente el Grupo de Estudios de Historia de la Guerra (GEHiGue) del Instituto de Historia Argentina y Americana «Dr. Emilio Ravignani» y cuyas publicaciones, nutridas por las perspectivas de la historia global y la historia social, han venido ayudando a consolidar en la región una nueva mirada sobre los conflictos bélicos.

Ponemos fin a este proemio con un pequeño pie circunstancial y extratextual. La preparación del dossier «Revistas culturales en tiempos de guerra» no escapó a las dificultades impuestas por la instalación de la pandemia de Covid-19 en 2020 y su continuidad hasta el cierre de la edición. Atendiendo a esto, queremos concluir la presentación de este número expresando nuestro más sincero agradecimiento a los autores y evaluadores que tan generosamente contribuyeron con estas páginas que hoy salen al encuentro de sus lectores.

Nicolás Arenas Deleón Universidad de los Andes, Chile. narenas@miuandes.cl

ORCID iD: https://orcid.org/0000-0002-5087-5839

Para citar este artículo / To reference this article / Para citar este artigo Moraes Medina, Mariana y Nicolás Arenas Deleón. Revistas culturales en tiempos de guerra. Humanidades: revista de la Universidad de Montevideo, n 9, (202 I): I I - 18. https://doi.org/I 0.25 I 85/9. I la investigación de este estudio y Nicolás Arenas Deleón del 50\% restante. 